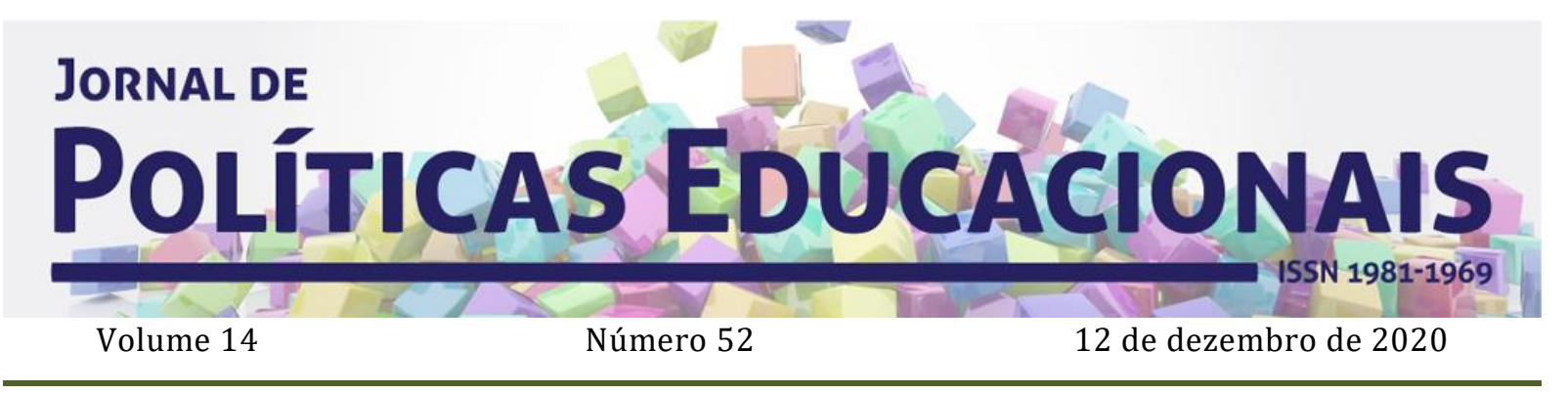

\title{
Crítica ao programa FUTURE-SE: autonomia como dispositivo de desativação do papel do Estado sobre Institutos e Universidades Federais
}

\section{Critique of the "FUTURE-SE" program: autonomy as a deactivation device of the state role on Federal Institutes and Universities.}

\section{Crítica al programa "FUTURE-SE": la autonomía como dispositivo de desactivación del papel del Estado sobre los Institutos y Universidades Federales}

Fernando Lionel Quiroga ${ }^{1}$

Citação: QUIROGA, F. L. Crítica ao programa FUTURE-SE: autonomia como dispositivo de desativação do papel do Estado sobre Institutos e Universidades Federais. Jornal de Políticas Educacionais. V. 14, n. 52. Dezembro de 2020.

http://10.5380/jpe.v14i0.74230

\section{RESUMO}

O presente ensaio consiste de uma análise crítica ao projeto de lei Programa Institutos e Universidades Empreendedoras e Inovadoras - FUTURE-SE. Tal crítica toma por base dois eixos principais: a) o temperamento político do governo de extrema-direita de Jair Bolsonaro e seus ministros, cujas declarações públicas assumem um tom de ameaça constante à democracia e; b) o projeto de lei (PL) como objeto de valor jurídico que permite a materialização de tais declarações. A composição de tais eixos abre espaço para a interpretação de que os objetivos subjacentes ao programa consistem em um conjunto de dispositivos cuja finalidade reside no esforço de desativar o papel do Estado sobre os Institutos e Universidades Federais. Tal hipótese evidencia-se pelo caráter genérico e impreciso com que são tratados diversos pontos em razão de uma ausência de concepção ampla de universidade e de outros conceitos-chave ao projeto, como o de autonomia. Cabe destaque a recepção negativa do projeto pelas Universidades Federais, que manifestaram um quadro de rejeição praticamente unânime (ANDIFES). Por essa razão, face a maciça repercussão negativa que o projeto adquiriu logo após seu lançamento, podemos concluir que, embora talvez esta peça não surta o efeito esperado pelos seus idealizadores - o futuro do próprio ministro encontra-se comprometido após suas declarações sobre o STF - deve-se estar atento a novas tentativas de golpe.

\footnotetext{
${ }^{1}$ Doutor e Mestre em Ciências pelo programa Multidisciplinar: Educação e Saúde na Infância e na Adolescência - Universidade Federal de São Paulo, UNIFESP, com estágio de pós-doutorado em Filosofia da Educação pela Universidade de São Paulo (USP). Professor Efetivo da Universidade Estadual de GoiásFundamentos da Educação. Anápolis, GO, Brasil. Orcid: https://orcid.org/0000-0003-4172-2002. E-mail: fernando.quiroga@ueg.br
} 
QUIROGA, F. L. Crítica ao programa FUTURE-SE: autonomia como dispositivo de desativação do papel do Estado sobre Institutos e Universidades Federais

Palavras-Chave: Future-se; democracia; Estado; neoliberalismo.

\section{ABSTRACT}

The present essay consists of a critical analysis of the law project "Programa Institutos e Universidades Empreendedoras e Inovadoras" (Entrepeneurs and Innovative Universities and Institutes Program) "FUTURE-SE" (something as "Future yourself", with the noun "future" beeing used as a verb). This criticism is based on two main axes: a) the political temperament of the extreme right government of Jair Bolsonaro and his ministers, whose public declarations assume a tone of constant threat to democracy; b) the bill of law (PL, for Projeto de Lei) as an object of legal value that allows a material viability of such declarations. A composition of these axes opens space for the following interpretation, that the objectives underlying the program consist of a set of devices whose final effort resides in changing the role of the State over Federal Institutes and Universities. Such hypothesis proves itself by the generical character and the imprecision with which several points of the project are treated, which are due to the lack of breadth of the concept of University and other key concepts of the same project, such as University autonomy. It is worth mentioning the negative reception of the project by the Federal Universities, which manifests itself in a context of practically unanimous rejection (ANDIFES, Brazilian association of Federal Universities). For this reason, facing the huge negative repercussion that the project acquired after its launch, one may conclude that it might not have the effect expected by its creators - the future of the minister himself is compromised after his statements on the STF (Brazilian Supreme Court) - anyway, one must be aware of new coup attempts. Key words: Future-se; democracy; State; neoliberalism.

\section{RESUMEN}

El presente ensayo consiste en un análisis crítico del proyecto de ley de Emprendedores e Institutos Innovadores y Programa Universitario - FUTURE-SE. Esta crítica se basa en dos ejes principales: a) el temperamento político del gobierno de extrema derecha de Jair Bolsonaro y sus ministros, cuyas declaraciones públicas asumen un tono de amenaza constante a la democracia y; b) la factura (PL) como un objeto de valor legal que permite la viabilidad material de tales declaraciones. La composición de tales ejes abre el espacio para la interpretación de que los objetivos subyacentes al programa consisten en un conjunto de dispositivos cuyo propósito radica en el esfuerzo por desactivar el papel del Estado sobre los Institutos y Universidades Federales. Esta hipótesis se evidencia por el carácter genérico e impreciso con el que se tratan varios puntos del proyecto debido a la ausencia de una concepción amplia de la universidad y otros conceptos clave del proyecto, como la autonomía. Cabe destacar la recepción negativa del proyecto por parte de las Universidades Federales, que manifestó una situación de rechazo prácticamente unánime (ANDIFES). Por esta razón, en vista de las enormes repercusiones negativas que adquirió el proyecto poco después de su lanzamiento, podemos concluir que, aunque tal vez esta pieza no tenga el efecto esperado por sus creadores, el futuro del propio ministro se ve comprometido después de sus declaraciones sobre el STF - uno debe estar al tanto de los nuevos intentos de golpe.

Palabras clave: Future-se; democracia; Estado; neoliberalismo

"O que o governo vai fazer por vocês? Nada! Vocês têm que se virar" (Ministro da Educação A. Weintraub, em pronunciamento no 21 ${ }^{\circ}$ Fórum de Ensino Superior (Fnesp)).

"[...] idiotas úteis, uns imbecis que estão sendo usados como massa de manobra de uma minoria espertalhona que compõe o núcleo de muitas universidades federais do Brasil." (Jair Bolsonaro, Presidente do Brasil, em Dallas, a respeito das manifestações populares depois do cortes na educação, em 15/05/2019). 


\section{Introdução}

0 presente ensaio tem por objetivo analisar criticamente o projeto de lei (PL) do Programa Institutos e Universidades Empreendedoras e Inovadoras - FUTURE-SE. Diversos aspectos do programa chamam a atenção. Em especial, destaca-se o caráter impositivo: a proposta chegou pronta, sem contar com a participação de especialistas e pesquisadores da área, além da comunidade que compõe as universidades e institutos técnicos federais. Mais: o projeto veio a público em um momento em que as universidades e institutos passavam por uma crise decorrente de um bloqueio de $30 \%$ de seu orçamento, cuja justificativa apareceu somente mais tarde, quando o presidente e o ministro afirmaram se tratar de um contingenciamento em razão da baixa arrecadação de impostos e queda na economia. Ademais, não se pode perder de vista o fato de que no mesmo contexto havia uma pressão para a aprovação da reforma previdenciária, cujos efeitos produziriam a recuperação econômica. Em outras palavras: a razão central do corte consistia em demonstrar a fragilidade econômica e pressionar a aprovação da reforma. Além disso, produzia-se a mensagem clara, desta vez direcionada aos institutos e universidades, de que chegara a hora destas instituições buscarem sua independência financeira, desenvolvendo uma cultura empreendedora treinada para captar recursos.

A margem para esta interpretação é clara: a agenda ultraliberal do governos de extrema direita não possui qualquer intenção em fortalecer as instituições sob a responsabilidade do Estado. O PL consiste, portanto, em uma política pública que induz a uma redução drástica do papel do Estado. Trata-se de uma política pública de viés privado.

Metodologicamente este trabalho consiste em uma análise documental que toma como base o projeto de Lei do programa FUTURE-SE e de leituras complementares, especialmente a análise preliminar realizada pela Universidade Federal de Pelotas, UFPel $^{2}$.

O documento (PL) está dividido nas seguintes partes: 1) Objetivos Gerais; 2) Operacionalização; 3) Papel das Organizações Sociais; 4) Fomento; 5) Eixo 1: Governança,

\footnotetext{
2 FUTURE-SE: UMA ANÁLISE PRELIMINAR DA ADMINISTRAÇÃO DA UNIVERSIDADE FEDERAL DE PELOTAS. Disponível em: http://ccs2.ufpel.edu.br/wp/2019/07/23/ufpel-lanca-analisesobre-0-FUTURE-SE/ Acesso em 20/04/2020.
} 
Gestão e Empreendedorismo; 6) Eixo 2: Pesquisa, Desenvolvimento e Inovação; 7) Eixo 3: Internacionalização; 8) Fundo; 9) Comitê Gestor.

Entre seus conteúdos não se vê (ou se vê vagamente) qualquer menção ao ensino, papel e responsabilidade social da universidade pública; inclusão social; proposta de expansão na oferta do número de vagas; articulação entre as diversas áreas do conhecimento e sua igual valorização; extensão universitária, dentre outras características óbvias para um entendimento democrático da universidade brasileira. $\mathrm{Na}$ contramão disso, o documento, em seu título, mostra o seu perfil privatista.

\section{Dos objetivos gerais do PL}

Nos objetivos gerais do documento consta que o Programa "tem por finalidade o fortalecimento da autonomia administrativa, financeira e de gestão das Instituições Federais de Ensino Superior (Ifes), por meio de parceria com organizações sociais e do fomento à captação de recursos próprios". Ocorre que o conceito de autonomia, aqui, não significa que a gestão das universidades e institutos poderá ser realizada de modo independente quanto ao planejamento de alocação dos recursos da União, mas que tal independência será o resultado das ações de empreendedorismo e eficiência na captação de recursos. 0 viés objetivamente mercadológico aproxima-se do entendimento de que a universidade, sob esta concepção, deve-se restringir apenas a uma elite intelectual, como afirmou o ex-ministro da educação Ricardo Vélez em entrevista no Valor Econômico, na medida em que a formação de profissionais pode ser realizada com um custo bem abaixo do que é gasto pela formação universitária. Trata-se de um tipo de concepção que vê sentido apenas sobre aquilo que produz algum retorno imediato à sociedade. A base desta concepção encontra sustentação em uma frase do próprio presidente da república, que publicou no Twitter a seguinte mensagem:

O Ministro da Educação @abrahamWeinT estuda descentralizar investimento em faculdades de filosofia e sociologia (humanas). Alunos já matriculados não serão afetados. 0 objetivo é focar em áreas que gerem retorno imediato ao contribuinte, como: veterinária, engenharia e medicina [April 26, 2019].

Trata-se de uma concepção rudimentar de universidade. Rudimentar e ignóbil, pois ignora que até o produto menos complexo passou por um longo processo de 
amadurecimento e aperfeiçoamento do conhecimento; imagina que a reprodutibilidade técnica de caráter imediatista seja uma consequência natural da modernidade, e não outra consequência do pensamento que é decantado lentamente nas universidades e que depende de tempo e investimento. Assim, a noção de "futuro", presente no nome do programa nada tem a ver com a relação temporal passado-presente-futuro, mas com um tipo de transferência de responsabilidade, semelhante a que as famílias pobres fazem aos seus filhos por não terem condições de sustentá-los e que, aqui, poderíamos traduzir pela expressão popular: "se vira!"!

Esta imagem comparativa, ademais, expressa o modo como o governo de extrema direita vê a responsabilidade do Estado frente a coisa pública. Transmite-se a falsa analogia entre paternalismo e papel do Estado, induzindo o cidadão a pensar que o futuro depende apenas de seus esforços pessoais, de modo que as decisões políticas não possuam qualquer relação aos seus êxitos ou fracassos, a sua felicidade ou infelicidade. 0 cidadão é constrangido a pensar que o Estado não possui responsabilidade sobre a condições materiais e simbólicas que preenchem a sua existência. De todo modo, tal noção é sustentada pela ideologia da meritocracia, cuja base assenta-se no paternalismo, isto é, na junção intencional da vida pública à privada; uma das premissas, aliás, dos governos de extrema direita. Nitidamente percebe-se uma falta de clareza quanto a concepção de universidade, que deveria balizar todo o projeto.

A respeito dos compromissos que as Ifes deverão assumir depois de aderirem ao programa, o documento estabelece:

\footnotetext{
I - utilizar a organização social contratada para o suporte à execução de atividades relacionadas aos eixos previstos no $\S 1^{\underline{0}}$ do art. $1^{\underline{0}}$, desenvolvidas nos institutos e nas universidades federais; II - adotar as diretrizes de governança dispostas nesta Lei, inclusive ao Sistema de Governança a ser indicado pelo Ministério da Educação; e III - adotar programa de integridade, mapeamento e gestão de riscos corporativos, controle interno e auditoria externa [BRASIL/MEC, 2019].
}

Nesta descrição, especialmente no item dois, o documento desloca as diretrizes para o campo indefinido e incerto do futuro; o texto dá margens para a interpretação de que a autonomia recém prometida é imediatamente retirada. Estranhamente não se verifica, aqui também, nenhuma menção à democracia como, aliás, em nenhuma parte do documento. Um sinal de que o que está em questão, mais do que um programa, é um projeto deliberadamente pensado para mudar o espírito da universidade, desvinculando- 
QUIROGA, F. L. Crítica ao programa FUTURE-SE: autonomia como dispositivo de desativação do papel do Estado sobre Institutos e Universidades Federais

a da responsabilidade do Estado. Como política neoliberal, o programa é um instrumento de desativação do jogo democrático, como assinalam Laval e Dardot (2016) em A nova razão do mundo.

\section{Da Operacionalização}

Art. 3ํㅜ A operacionalização do programa dar-se-á por meio de contratos de gestão, firmados pela União e pela IFES, com organização social, cujas atividades sejam dirigidas ao ensino, à pesquisa, ao desenvolvimento, à inovação, à proteção e preservação do meio ambiente, à cultura, à saúde e estejam relacionadas às finalidades do Programa [IDEM, 2019].

Além da ausência de clareza quanto as dimensões aqui elencadas, verifica-se ainda a omissão sobre outras não menos importantes, como a extensão, a inclusão social, o papel e responsabilidade da universidade com as culturas indígena e quilombola ${ }^{3}$ etc. 0 que está em questão, e que deve ser analisado, é que tal omissão faz parte de um cálculo que merece nossa atenção. 0 que se revela por meio deste e de outros programas semelhantes, em todas as áreas, é uma mudança drástica de comportamento; uma mudança radical nas relações humanas. Nas palavras de Laval e Dardot:

Não podemos esquecer jamais que a expansão das finanças de mercado, assim como o financiamento da dívida pública nos mercados de títulos, são fruto de políticas deliberadas. Como se vê até mesmo na atual crise na Europa, os Estados adotam políticas altamente "intervencionistas", que visam a alterar profundamente as relações sociais, mudar o papel das instituições de proteção social e educação, orientar as condutas criando uma concorrência generalizada entre os sujeitos, e isso porque eles próprios estão inseridos num campo de concorrência regional e mundial que os leva a agir dessa forma [LAVAL e DARDOT, 2016, p. 17 - grifo nosso].

A ausência de consideração das dimensões sociais que necessitam de maior presença e proteção do Estado, e a semântica empresarial de olhar economicista que estimula o empreendedorismo, partem de um mesmo sistema de crenças daqueles que

\footnotetext{
${ }^{3}$ Na reunião ministerial de 22 de abril deste ano, o Ministro da Educação Abraham Weintraub fez a seguinte afirmação: "Ele tá querendo transformar a gente numa colônia. Esse país não é... odeio o termo 'povos indígenas', odeio esse termo. Odeio. O 'povo cigano'. Só tem um povo nesse país. Quer, quer. Não quer, sai de ré". Em outra ocasião, o presidente Jair Bolsonaro, durante palestra na comunidade judaica, afirmou: "Eu fui num quilombo. 0 afrodescendente mais leve lá pesava sete arrobas. Não fazem nada. Eu acho que nem para procriador ele serve mais. Mais de $\mathrm{R} \$ 1$ bilhão por ano é gasto com eles".
} 
viam no surgimento da social-democracia do New Deal e o estado de bem-estar britânico como uma ameaça tão perigosa quanto o nazismo ou comunismo (Carvalho, 2018, p. 124).

Quanto a seção III, que trata das Competências e deveres da Organização Social contratada, merece atenção a cedência dos servidores federais às organização sociais, como consta no artigo 5, II: "remuneração de seus colaboradores, inclusive dos servidores cedidos". O PL não justifica o porquê da cedência, deixando clara a intenção de desresponsabilizar o Estado quanto ao pagamento do salário do servidor. Como não há detalhes sobre o percentual de servidores cedidos, nem algo que o justifique, depreendese que possam existir mecanismos administrativos que não deem outra alternativa ao servidor do que aceitar sua cessão a uma OS e, consequentemente, ver-se despido das garantias trabalhistas inerentes ao cargo que ocupa. 0 maior risco, aliás, talvez resida na hipótese assinalada pela análise preliminar da administração da Universidade Federal de Pelotas ao questionar que:

Se a ideia de cedência dos servidores efetivamente for confirmada, faltou mencionar no item sobre fomento do programa que a transferência de servidores públicos para a organização social é a principal fonte de financiamento do programa [UFPEL, 2019, p. 60].

Aqui, manifesta-se sob a sombra da lei o verdadeiro conteúdo do projeto, traduzido em um linguajar direto e incisivo, sempre com o objetivo de dialogar com seu eleitorado, como quando o Ministro da Educação A. Weintraub afirmou ser necessário acabar com as "zebras gordas" das universidades, referindo-se àqueles professores que ganham entre R\$ 15 e R\$ 20 mil reais mensais. Além do mais, na concepção simplista do Ministro, ignorando a divisão da composição da carga horária, que inclui os pilares da pesquisa e da extensão universitária, a injustiça do salário se deve ao fato do professor dar apenas 8 horas de aula semanais ${ }^{4}$. A questão é que o ministro não ignora a composição horária; antes, sua preocupação consiste em atingir as massas tanto quanto o puder, criando um clima de hostilidade na opinião pública acerca da educação e utilizando-se da estratagema do bode expiatório em favor do menos favorecidos: curiosamente uma súbita preocupação com as crianças desassistidas pela falta de cobertura de creches públicas, cujo sofrimento se deve aos privilégios e regalias dos professores universitários. De um

\footnotetext{
${ }^{4} 0$ pronunciamento, de aproximadamente 20 minutos, ocorreu no 21ํㅡórum de Ensino Superior (Fnesp).
} 
QUIROGA, F. L. Crítica ao programa FUTURE-SE: autonomia como dispositivo de desativação do papel do Estado sobre Institutos e Universidades Federais

lado, um autêntico Chicago Boy; de outro, um Harry Hopkins ${ }^{5}$ preocupado em promover bem-estar social.

\section{Do Fomento}

Este é o coração do programa pois, afinal, é o que trata dos recursos. Aqui evidencia-se o temperamento neoliberal, cujo proposito consiste na supressão total do Estado e da democracia para impor, em sua integralidade, as leis do mercado empresarial. Todo o texto abre margem à dedução da transferência total da responsabilidade do Estado à iniciativa privada. Não há nenhuma ênfase quanto a garantia de recursos da União destinados ao ensino superior. Ao contrário, o que se depreende da fala do ministro A. Weintraub é que os gastos com esta modalidade tem sido tratada em pé de guerra, como evidencia-se nesta declaração:

Mais de $80 \%$ do ensino superior está na iniciativa privada e o MEC tem uma folha de pagamento com professores federais que cresce $8 \%$ ao ano sem eu fazer nada. Metade do 600 mil servidores da República está no MEC, 300 mil. Eu tenho que enfrentar este exército. Dentre outras coisas, doutrinação, metodologia de alfabetização totalmente errada, gastam-se fortunas na universidade enquanto o filho do pobre não vai para a préescola (ANDES, 2019).

O contexto e o clima beligerante que o atual governo e seus ministros adotam a respeito de políticas públicas essenciais, como educação, saúde, segurança pública, e o modo como dialogam estrategicamente com a imprensa, atacando aos jornalistas e criando notícia sobre notícia, isto é, uma notícia (que deveria ser a principal) e a do ataque ao jornalista e a imprensa, sinalizam claramente de que se trata de um governo autocrático. Se o Chile foi o laboratório para a doutrina de choque do neoliberalismo dos anos 1970, o Brasil é o laboratório do atual neoliberalismo, isto é, um neoliberalismo que prescinde de tanques de guerra desfilando pelas ruas, já que a dominação ocorre primeiramente e em larga escala pela via ideológica, utilizando-se como armas as redes

\footnotetext{
${ }^{5}$ Harry Hopkins 1890-1946 foi um assistente social americano e secretário de Comércio dos Estados Unidos, conhecido por ser um dos conselheiros mais próximos do Presidente Franklin Delano Roosevelt, a quem se atribui o New Deal, uma série de programas implementados pelos Estados Unidos entre os anos 1933 e 1937 que tinha por objetivo de recuperar a economia depois da Grande Depressão dos anos 1930, iniciada em 1929.
} 
QUIROGA, F. L. Crítica ao programa FUTURE-SE: autonomia como dispositivo de desativação do papel do Estado sobre Institutos e Universidades Federais

sociais e demais possibilidades de disseminação de informações e notícias deliberadamente imprecisas ou falsas.

\section{Da gestão, da governança e do empreendedorismo}

No capítulo II, seção I - Da governança, o que se observa, como na totalidade do texto, é a prevalência da semântica empreendedora, mercadológica, tendo como foco a gestão em prol de resultados imediatos e que gerem resultados imediatos. Na ausência de uma concepção bem fundamentada e bem pensada da universidade, como apontado anteriormente, insere-se uma concepção de mercado, tratando a instituição como um órgão complementar ou e de pouca importância, e não central como deveria ser.

Quanto a transparência, por exemplo, o conteúdo do artigo 13 consta:

[...]As IFES que aderirem ao programa, deverão observar, no mínimo, os seguintes requisitos de transparência:

I - elaboração de carta anual, com a explicitação dos compromissos de consecução de objetivos de políticas pela IFES, com definição clara dos recursos a serem empregados para esse fim, bem como dos impactos econômico-financeiros da consecução desses objetivos, mensuráveis por meio de indicadores objetivos;

II - divulgação tempestiva e atualizada de informações relevantes, em especial as relativas a atividades desenvolvidas, cursos ofertados, índices de evasão e descrição da composição da remuneração dos servidores; e III - elaboração de política de divulgação de informações, em conformidade com a legislação em vigor e com as melhores práticas.

Parágrafo único. Os documentos resultantes do cumprimento dos requisitos de transparência constantes dos incisos do caput deverão ser publicamente divulgados na internet de forma permanente e cumulativa [BRASIL/MEC, 2019].

Ninguém que respeita a democracia questionaria a preocupação com a transparência. Contudo, há sempre o risco iminente de uma confusão entre o que se restringe à dimensão da transparência, como prestação de contas à sociedade, e o que pode ser um mecanismo de controle que prejudica o funcionamento institucional em sua total dimensão. Ao não se mencionar em nenhuma parte do PL a preocupação com os cursos das Ciências Humanas, cujo valor da produção não possui qualquer relação com o tipo de produto que atenda as demandas imediatas da sociedade. 0 absurdo da proposta consiste no fato de que se houvesse qualquer verossimilhança da objetividade empreendedora com a realidade universitária, seria comum buscarmos respostas aos problemas humanos em escritórios contábeis de filosofia medieval, corporações de 
antropologia cultural, consultórios de sociologia, sistemas de gestão de física pura, clínica histórica do antigo ao novo regime, etc.

Mais uma vez o que se percebe é a falta de adequação do projeto a uma ampla e profunda concepção de universidade que deveria, em tese, balizar as políticas de planejamento e gestão, evitando o estrangulamento que o movimento oposto produz ao fazer com que as universidades se adequem aos princípios do empreendedorismo, nem sempre afinados à realidade universitária. Com efeito, o que parece ocultar-se no PL, que busca desresponsabilizar o Estado, é a asfixia, pela via econômica, dos cursos das Ciências Humanas como Filosofia e Sociologia - curiosamente os cursos em que se produz conhecimento crítico, em grande parte contrários as tendências fascistas e totalitárias com as quais flerta o atual governo, de modo muitas vezes explícito.

Por detrás do disfarce da ideia de "transparência", evidencia-se um dispositivo de controle empresarial que sistematicamente reduz todas as variáveis dos investimentos nos institutos e universidades ao cálculo econômico. Em suma, reduz-se a concepção de universidade a um olhar meramente economicista.

No capítulo III, da Pesquisa, do Desenvolvimento e da Inovação, destacamos o seguinte trecho:

II - aprimorar as atividades de pesquisa, desenvolvimento e inovação, de nível nacional e internacional, buscando disseminar a cultura da inovação, da propriedade intelectual e da transferência de tecnologia [IDEM, 2019].

O PL força uma associação monocrática entre pesquisa e inovação, não fazendo qualquer menção a pesquisas sem potencial de inovação. Ao mesmo tempo, deixa clara a intenção em disseminar a cultura da inovação, evidenciando que esta deve ser predominante na universidade e não apenas uma frente, vinculada aos campos de pesquisa com este potencial. Tal perspectiva sinaliza um olhar depreciativo a respeito de pesquisas sem aplicabilidade imediata às demandas do mercado, empurrando ainda mais estes campos à margem da universidade, já pouco contemplados pelas agências de incentivo e financiamento à pesquisa. Da mesma forma que falta uma concepção de universidade, verifica-se, neste capítulo, a mesma lacuna em relação a pesquisa. A pesquisa, aqui, é reduzida a uma concepção meramente mercadológica. Este olhar fragmentado da universidade, aliás, uma vez que desarticula os campos do conhecimento - caminhando em sentido contrário à tendência contemporânea da multidisciplinaridade 
QUIROGA, F. L. Crítica ao programa FUTURE-SE: autonomia como dispositivo de desativação do papel do Estado sobre Institutos e Universidades Federais

- transforma o espaço universitário em espaço para conhecimento técnico, deslocando para segundo plano as tradicionais áreas do conhecimento.

Além do fato do projeto deixar clara sua intenção em modificar a cultura da universidade, transformando-a em uma instituição de viés exclusivamente empreendedor, reforça, por outro lado, a transferência quanto aos recursos e valores, que devem ser de natureza privada. Quanto aos recursos, nada do estado; quanto as ideias, tudo. A atuação do Estado, aqui, assemelha-se em tudo ao que instituições como o Banco Mundial fazem, emitindo diagnósticos e relatórios de modo intervencionista de modo a estimular, no plano das ideias, a formulação de políticas educacionais nos países em desenvolvimento. Na metáfora cirúrgica de Coraggio (2000), para quem as políticas sociais seriam como o "Cavalo de Tróia"6, também o FUTURE-SE reveste-se da mesma roupagem. Na medida em que promete fortalecer a autonomia administrativa e financeira das Instituições Federais de Ensino Superior - IFES, o faz sob mecanismos jurídicos que permitem esvaziar o papel do Estado, transferindo sua responsabilidade para as organizações sociais, que deverão concentrar esforços na busca de recursos de natureza privada.

No capítulo IV, da Internacionalização, salta à vista o item I do artigo 20: "I - a realização de cursos de idiomas para os docentes, por meio de parcerias com instituições privadas, para promover a publicação em periódicos no exterior [MEC/BRASIL, 2019]". Destacamos, com estranheza, a conexão imediata que se faz acerca da aprendizagem de cursos de idiomas por meio de parcerias com instituições privadas, desconsiderando a viabilidade com as quais tais parcerias poderiam ser feitas com as próprias instituições federais, como assinalado pelo documento da UFPel. Ao preterir o conhecimento e domínio de certas competências que são produzidas nas instituições públicas, privilegiando aquelas das instituições privadas, sente-se o que Jessé Souza, em diversas obras, chamou de complexo de vira-lata, isto é, um sentimento de inferioridade sobre os verdadeiros valores nacionais, decorrente de uma "divinização" dos países centrais, em especial os Estados Unidos, que são aqui simbolizados por uma concepção de que o que é privado é sempre melhor que o público - ideia hegemônica da classe média reacionária. Veja-se, por exemplo, o que diz o Art. 21 do projeto:

\footnotetext{
${ }^{6}$ Em sua crítica as propostas do Banco Mundial para a educação, o autor escreve: "as políticas sociais são elaboradas para instrumentalizar a política econômica, mais do que para continuá-la ou compensá-la. São o "Cavalo de Tróia" do mercado e do ajuste econômico no mundo da política e da solidariedade social" (CORAGGIO, 2000, p. 78).
} 
Art. 21. Ato do Poder Executivo disciplinará a política de internacionalização de conhecimento, dispondo sobre a organização e gestão dos processos, de modo a assegurar:

I - o fluxo contínuo de intercâmbio de professores, fomentando a pesquisa e uma melhor colocação nos índices e rankings internacionais [IBIDEM, 2019].

O item I dá margem para que se pense que a melhoria nos rankings estaria condicionada ao intercâmbio de professores e não em decorrência da qualidade das pesquisas, que dependem de investimento e condições favoráveis para que sejam realizadas. 0 estímulo ao intercâmbio faria mais sentido se, ao invés de pensar na posição de rankings como finalidade, houvesse uma preocupação central com a qualidade e o impacto social, a preservação do meio ambiente e das culturas e o caráter multidisciplinar de suas investigações.

\section{Considerações Finais}

Reúnam-se para buscar solução. Organizem-se rapidamente. O Estado não existe. O Estado tem que ser diminuído para permitir que nós possamos buscar nossa felicidade. O lucro foi amaldiçoado, mas lucro é diferente de roubo. Lucro é resultado de trabalho honesto. Aproveitem. (Ministro da Educação A. Weintraub, em pronunciamento no 21ํㅡórum de Ensino Superior (Fnesp)).

Universidade "não é para todos, mas somente para algumas pessoas" (Ricardo Vélez Rodriguez, ex-ministro da Educação, em 30/01/2019 - por meio de vídeo publicado em sua conta no Twitter).

O projeto se encerra com as disposições acerca do fundo e do comitê gestor. Merece destaque o caráter não consensual das administrações do Ifes acerca da cobrança de matrículas em cursos de pós-graduação lato sensu, já que muitas partilham do entendimento acerca do princípio da gratuidade, que deve ser assegurado em instituições de caráter público. Embora o PL apresente-se com a ideia de ampliação orçamentária, não enfatiza a responsabilidade do poder público sobre o garantias em relação ao financiamento ou sobre mecanismos de manutenção da qualidade para todos os cursos, em todas as suas dimensões: ensino, pesquisa e extensão. Como a noção de autonomia aproxima-se, no corpus do projeto, a de "descolamento" do poder do Estado - noção adensada pelo contexto político e seus dispositivos ideológicos a serviço da demonização 
do Estado - é possível interpretar o projeto como uma primeira investida a favor da total privatização do ensino superior, isto é, sua total desativação do Estado.

Ao ser apresentada como condição facultativa, a proposta parece querer revestirse de uma aura democratizante, embora a privação de um debate preliminar acerca de sua formulação aponte justamente o contrário.

Felizmente a maior parte dos institutos e universidades já sinalizaram e manifestaram seu descontentamento ao projeto, muitas externando à comunidade sua integral rejeição (ANDIFES). Tamanha reação é a comprovação de que o conteúdo do projeto constitui uma ameaça revestida com a promessa de ampliação da autonomia orçamentária. A falta de clareza e maior detalhamento e profundidade, a ausência de uma concepção consistente de universidade e, mais grave, a exclusão de pesquisadores, gestores e da própria comunidade para um debate prévio à formulação da proposta são aspectos decisivos que permitem concluir que o PL não merece sequer um debate de ajuste, visando uma adequação aos princípios da universidade. Constata-se, com efeito, e parafraseando mais uma vez Coraggio (2000), um problema de concepção na proposta. É a sua origem que compromete o seu modus operandi. Sugere-se, portanto, a rejeição maciça do PL para que os institutos e universidades possam debater coletivamente, junto à sociedade, seus problemas e buscar, democraticamente, soluções para o seu futuro.

\section{REFERÊNCIAS}

ASSOCIAÇÃO NACIONAL DOS DIRIGENTES DE INSTITUIÇÕES FEDERAIS DE ENSINO SUPERIOR. Veja as manifestações de algumas universidades federais sobre o programa FUTURE-SE. Brasília, DF: Andifes, 2018. Disponível em http://www.andifes.org.br/veja-manifestacoes-universidades-federais-sobre-future-se/ Acesso em: 20 jan. 2020.

BRASIL. Ministério da Educação. Projeto de Lei Programa Institutos e Universidades Empreendedoras e Inovadoras - FUTURE-SE. Disponível em: < http://portal.mec.gov.br/component/tags/tag/52641>. Acesso em 03 jan. 2020.

CARVALHO, L. Valsa Brasileira: do boom ao caos econômico. São Paulo: Todavia, 2019.

CORAGgIO, J. L. Propostas do Banco Mundial para a Educação: sentido oculto ou problemas de concepção. In: TOMMASI, L.; WARDE, M. J.; HADDAD, S. (Orgs.). O Banco Mundial e as políticas educacionais. 3. ed. São Paulo: Cortez, 2000. p. 75-124. 
QUIROGA, F. L. Crítica ao programa FUTURE-SE: autonomia como dispositivo de desativação do papel do Estado sobre Institutos e Universidades Federais

CRH-UFBa. Dossiê sobre o programa Future-se do Governo/MEC e as implicações para a Universidade e a sociedade. Grupo de Pesquisa Trabalho, Precarização e Resistências Centro de Estudos e Pesquisas em Humanidades/CRH-UFBa, Ago., 2019.

DARDOT, P.; LAVAL, C. A nova razão do mundo: ensaio sobre a sociedade neoliberal. São Paulo: Editora Boitempo, 2016.

SOUZA, J. A guerra contra o Brasil. Rio de Janeiro: Estação Brasil, 2020.

SOUZA, J.; et. al. A ralé brasileira: quem é e como vive. São Paulo: Editora Contracorrente, 2018.

UFPEL. Future-se: uma análise preliminar da administração da Universidade Federal de Pelotas. Disponível em http://ccs2.ufpel.edu.br/wp/2019/07/23/ufpel-lanca-analisesobre-o-FUTURE- SE/Acesso em 20/04/2020 

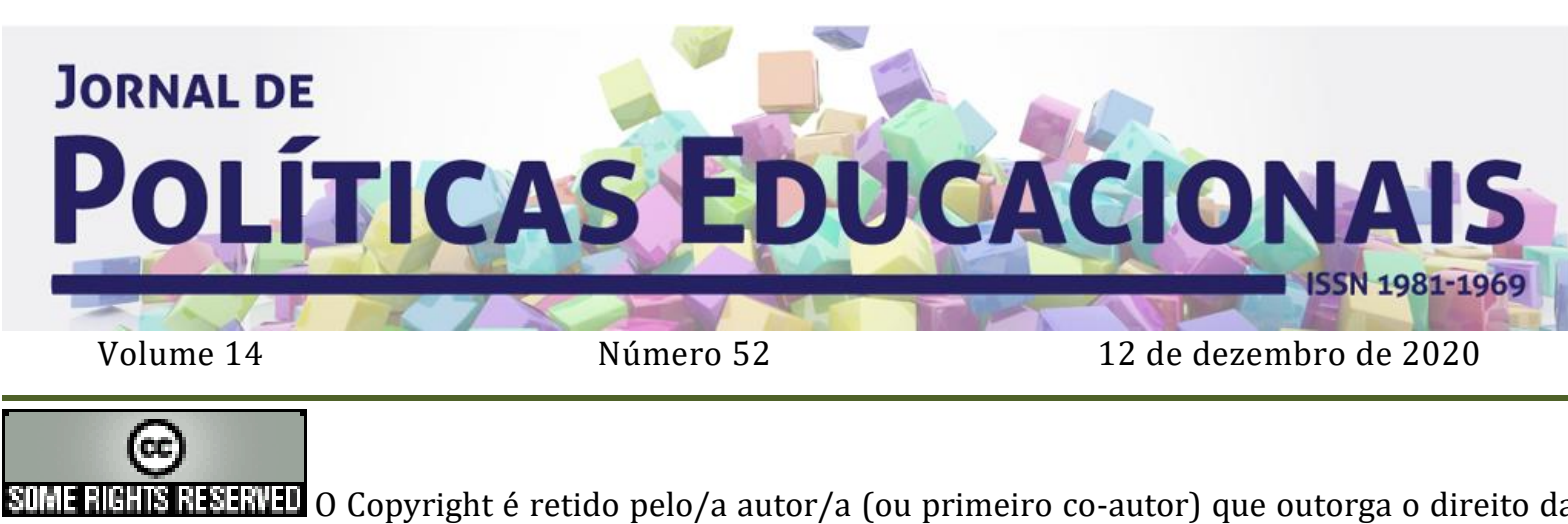

Jigright é retido pelo/a autor/a (ou pr primeira publicação ao Jornal de Políticas Educacionais. Mais informação da licença de Creative Commons encontram-se em http://creativecommons.org/licenses/by-nc-nd/2.5. Qualquer outro uso deve ser aprovado em conjunto pelo/s autor/es e pelo periódico.

JoRNAL DE POLÍTICAS EDUCACIONAIS é uma publicação do Núcleo de Políticas Educacionais do Setor de Educação da Universidade Federal do Paraná - NuPE/UFPR, em consórcio com a Linha de Pesquisa em Políticas Educacionais do Programa de Pós-Graduação em Educação - PPGE/UFPR, que aceita colaboração, reservando-se o direito de publicar ou não o material espontaneamente enviado à redação. As colaborações devem ser enviadas ao NuPE/UFPR, conforme orientações contidas nas páginas do periódico na internet: http://revistas.ufpr.br/ipe.

Indexação:

BBE - Biblioteca Brasileira de Educação (MEC/INEP)

Clase (Base de Datos Bibliográfica de Revistas de Ciencias Sociales y Humanidades)

Diadorim - Diretório de Política de Acesso Aberto das Revistas Científicas Brasileiras (IBICT)

Google Scholar

Index Copernicus

Portal de Periódicos (CAPES)

SER - Sistema Eletrônico de Revistas da Universidade Federal do Paraná (SER/UFPR)

Sumários de Revistas Brasileiras (FUNPEC-RP)

DRJI - Directory of Research Journals Indexing

(Periódico integralmente disponível apenas em via eletrônica)

Jornal de Políticas Educacionais / Núcleo de Políticas Educacionais da Universidade Federal do Paraná NuPE/UFPR - v.1, n. 1 (1o semestre de 2007) - Curitiba: NuPE/UFPR.

Volume 14, número 52 - Dezembro de 2020

ISSN 1981-1969

1. Educação - Periódicos. 2. Política Educacional - Periódicos. I. NuPE/UFPR

Comitê Editorial:

Elisângela Scaff (UFPR)

Daniela de Oliveira Pires (UFPR)

Conselho Editorial:

Andréa Barbosa Gouveia (UFPR - Brasil), Cesar Tello (Universidad Nacional Tres Febrero, Argentina), Fernanda Saforcada (Universidad de Buenos Aires - UBA - Argentina), Gladys Beatriz Barreyro (USP Brasil), Gustavo Enrique Fischman, (Arizona State University - USA), Jefferson Mainardes (UEPG - Brasil), João Ferreira de Oliveira (UFG - Brasil), Juca Gil (UFRGS - Brasil), Luiz Souza Júnior (UFPB - Brasil), Ney 
QUIROGA, F. L. Crítica ao programa FUTURE-SE: autonomia como dispositivo de desativação do papel do Estado sobre Institutos e Universidades Federais

Cristina Monteiro de Oliveira (UFPA - Brasil), Nicolás Bentancur, (Universidad de la República de Uruguay), Robert Verhine (UFBA - Brasil), Rosana Cruz (UFPI - Brasil), Rubens Barbosa Camargo (USP - Brasil), Sebastián Donoso Díaz (Universidad de Talca - Chile), TheresaAdrião (UNICAMP - Brasil), Vera Peroni (UFRGS - Brasil).

Créditos e Agradecimentos:

Revisão de Língua Portuguesa, Abstract e Resumen: PROGRAMA DE APOIO ÀS PUBLICAÇõES CIENTÍFICAS PERIÓDICAS DA UFPR

Arte e diagramação: TIAGO TAVARES (thiagotav@gmail.com)

Jornal de Políticas Educacionais

Universidade Federal do Paraná

Setor de Educação

Núcleo de Políticas Educacionais - NuPE/UFPR

Avenida Sete de Setembro, 2645

$2^{\circ}$ andar, Sala 213

80.230-010 - Curitiba - PR - Brasil

Tel.: 41-3535-6264

jpe@ufpr.br

http://revistas.ufpr.br/jpe 